Article

\title{
Analyzing the Drivers of Advanced Sustainable Manufacturing System Using AHP Approach
}

\author{
K. Madan Shankar ${ }^{1}$, P. Udhaya Kumar ${ }^{2}$ and Devika Kannan ${ }^{3, *}$ \\ 1 Department of Mechanical Engineering, PTR College of Engineering \& Technology, Madurai 625008, India; \\ mdnshankarr@gmail.com \\ 2 Department of Mechanical Engineering, KLN College of Engineering, Pottapalayam 630612, India; \\ kumarudhaya443@gmail.com \\ 3 Center for Engineering Operations Management, Department of Technology and Innovation, \\ University of Southern Denmark, Odense 5230, Denmark \\ * Correspondence: deka@iti.sdu.dk; Tel.: +45-6550-9499
}

Academic Editor: Marc A. Rosen

Received: 11 May 2016; Accepted: 12 August 2016; Published: 22 August 2016

\begin{abstract}
A number of current manufacturing sectors are striving hard to introduce innovative long-term strategies into their operations. As a result, many scholarly studies have found it fruitful to investigate advanced manufacturing strategies such as agile, computer-integrated, and cellular manufacturing. Through the example of downstream cases, manufacturing sectors have learned that financial benefits garnered through automated technologies cannot be counted on as a sole measure to ensure their success in today's competitive and fluctuating marketplaces. The objective of this study is to integrate those advanced techniques with sustainable operations, to promote advanced sustainable manufacturing so those manufacturing sectors can thrive even in uncertain markets. To establish this connection, this study analyzes the drivers of advanced sustainable manufacturing through a proposed framework validated through a case study in India. Common drivers are collected from the literature, calibrated with opinions from experts, and analyzed through an analytical hierarchy process (AHP), which is a multi-criteria decision making (MCDM) approach. This study reveals that quality is the primary driver that pressures manufacturing sectors to adopt advanced sustainable manufacturing. Manufacturers can easily note the top ranked driver and adopt it to soundly implement advanced sustainable manufacturing. In addition, some key future scopes are explored along with possible recommendations for effective implementation of advanced sustainable manufacturing systems.
\end{abstract}

Keywords: advanced sustainable manufacturing systems; drivers; AHP; MCDM

\section{Background}

Manufacturing is one of the world's most dynamic industries both in developed and developing nations. Because of manufacturing's broad scope, it attracts a multitude of developments and innovations, including advanced technologies that seek to add a benefit or to improve a process. Some advanced technologies consider green and lean practices, risk assessment, societal perspectives and so on [1-4]. Surprisingly, however, according to a report published by Infosys [5], whereas 85\% of advanced manufacturing techniques receive global acceptance, only $15 \%$ of organizations end up adopting those advanced processes. The Global Manufacturing Outlook report [6] finds that $48 \%$ of respondents vote to adopt new manufacturing technologies as efficient drivers for new growth and innovation in manufacturing sectors. Hence, with these considerations, this study chooses advanced manufacturing as a core of the research, in order to identify innovations related to sustainability. 
According to literature's definitions, advanced manufacturing technology is nothing but the application of innovative technology to make processes and systems work more efficiently.

If we identify 1960 as the starting point for advanced manufacturing systems, various strategies are grouped under that umbrella term. For instance, Tao et al. [4] identify a substantial list of manufacturing strategies; their list includes flexible, computer-integrated, cloud, additive, virtual, concurrent engineering, manufacturing grid, crowd sourcing, sustainable, agile, dynamic alliance, networked, lean, green, product service system, and reconfigured manufacturing.

The above-mentioned manufacturing technologies can be broadly classified into two groups with respect to their benefits. The first group features a "technological" approach and includes the first eight strategies: flexible, computer-integrated, cloud, additive, virtual, concurrent engineering, manufacturing grid, and crowd sourcing. Benefits from the technological group are designed to improve production and to increase financial profits.

The second group centers on all "environmental" strategies and include the techniques of sustainable, lean, and green manufacturing. The remaining five approaches do not fit precisely into either broad group, and therefore a discussion of those approaches shall be the focus of a future study. Obviously, the benefits from the second group emphasize social and environment concerns with little attention to finances. The majority of studies deal with only one of the above-mentioned manufacturing strategies. Zhu et al. [7], for example, studied energy optimization in sustainable manufacturing but did not touch on other technological perspectives. Rather than keeping a separate focus on the two strategy groups, organizations need to embrace both for maximum value creation. Hence, there is a need for scholarship that integrates the technology strategies with environmental and social concerns, as this study attempts to achieve. By combining advanced manufacturing with sustainable strategies, the four aspects of technical, technological, environmental, and societal values can be explored, resulting in the following research questions.

RQ1: What are the benefits of integrating sustainable strategies into advanced manufacturing and forming advanced sustainable manufacturing?

RQ2: What are the common drivers of advanced sustainable manufacturing to ensure its most effective implementation?

RQ3: Which is the most influential driver among common drivers of advanced sustainable manufacturing?

Among the above three research questions, the first question was already covered in the previous discussion, so the remaining two questions are considered the dominant focus. In order to address these primary questions, this study proposes a framework model that analyzes the drivers of advanced sustainable manufacturing. The proposed framework needs to be tested for reliability, so it will be applied to a case industry, and a South Indian firm has been selected. Many studies presume that developing nations are less accepting, less tolerant of new strategies, so our choice of a company in a developing nation presents an appropriate example with which to validate the proposed model. India is one of the globe's fastest growing nations; its significant population works hard to sustain their position in global manufacturing and to maintain societal and environmental health. The degree to which a company implements advanced sustainable manufacturing strategies has a direct impact on its performance level, and the challenges that company faces are significant. The proper use of land resources, human health, and economic instability are major issues faced by corporations, especially those in developing nations. Thus, it is even more important for manufacturing sectors in developing nations to enact sustainable strategies to combat the exploitation of natural resources. As two developing nations, China and India may initially be judged in similar terms, but a number of differences exist between them. The Indian context presents a better example by which to examine concepts of advanced sustainable manufacturing because no previous studies exist with that focus.

The remaining sections of the paper are organized as follows. Section 2 describes the research problem along with the proposed framework of the study. The methodology used for the solving the 
problem is given in Section 3 and includes a step-by-step explanation. Section 4 reports the application of the proposed model in the selected case industry with three phases of implementation. Sections 5 and 6 present results with corresponding discussions; these sections also provide the useful managerial implications of the study. Finally, the paper concludes with a summary of the findings, a statement of limitations, and some recommendations for future enhancements.

\section{Problem Description}

Competition resides at the heart of business, even for international companies. A primary goal for companies is to adopt manufacturing strategies that will help them to best compete successfully against other businesses. Manufacturers realize that technical advancements can help protect the firm from unexpected economic crises, and help them meet customer expectations when decreasing resources threaten the company. No studies currently exist that combine technological advancements with sustainable concerns, so this study seeks to integrate automation with sustainability in manufacturing sectors. The most common motivating factors are called drivers, so once drivers are clearly identified, it will be an easy task for manufacturers to use those drivers to improve their rate of advanced sustainable manufacturing. A model framework, shown in Figure 1, demonstrates the drivers of advanced sustainable manufacturing. Because the reliability of the proposed framework is under question unless it has been validated, this proposed framework was applied to a case industry situated in Indian geography. Generally, as discussed earlier, developing nations are still far behind in adopting efficient long-term strategies, so this study believes that a case study from India will make a significant contribution to the literature.

Framework of the study:

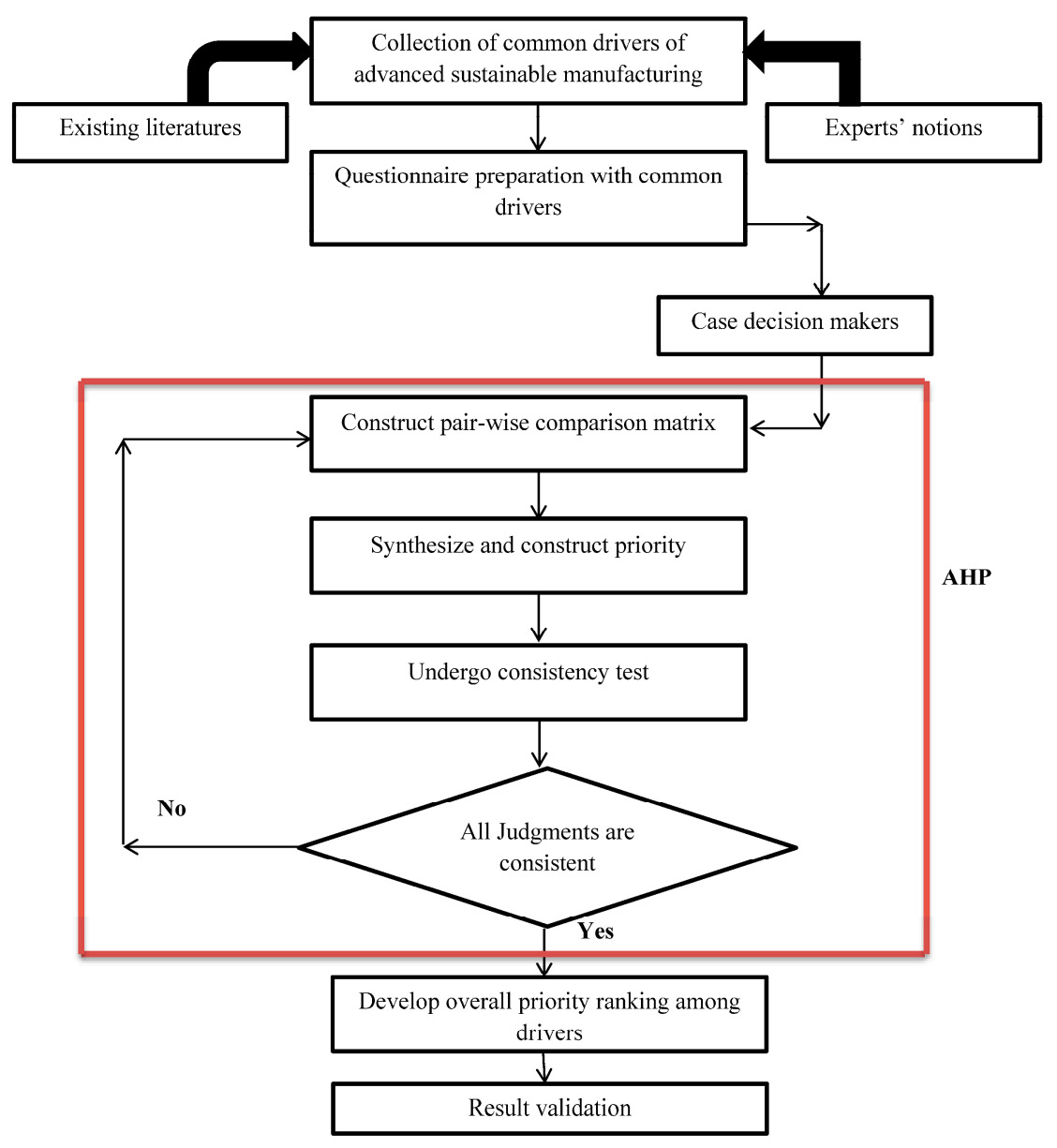

Figure 1. Proposed framework of the study. 
The proposed framework starts with the collection of common drivers of advanced sustainable manufacturing from the support of existing literatures and experts' notions. Once the common drivers are collected, a questionnaire is prepared along with a rating scale. From the replies of the case industry's decision makers, a pair-wise comparison is made among common drivers; this step is an initial process of AHP. The pair-wise comparison matrix is synthesized and the drivers' priority is constructed. Next, a consistency check is run to validate the AHP process. If the consistency check is successful, then the drivers' priority is revealed along with their corresponding ranks. Finally, the ranks are validated with the valuable feedback from the case industry's decision makers.

\section{Solution Methodology}

Advanced sustainable manufacturing provides an organization with many advantages but choosing an appropriate strategy is still a difficult task because, upon occasion, a company may face conflicting factors. In order to handle multi-criteria problems, this study features a multi-criteria decision making methodology. There are number of MCDM techniques available, but analytical hierarchy process (AHP) is among the most powerful. According to Lee and Drake [8] and Ishizaka et al. [9], AHP is a reliable tool in modern scenarios because it provides optimal solutions for many complex multi-criteria decision making problems. Originally proposed by Saaty in 1980, AHP has been applied in a variety of applications; it measures intangibles with the assistance of experts' judgments through pair-wise comparisons [10]. In AHP, complex problems are solved by inserting them into a hierarchical structure in order to measure the level of impact from one level to another. In addition, AHP is useful when a large number of factors are employed [11]. Some studies, for instance [12-18], articulate the advantages of AHP within their research; Liberatore and Nydick [19] argue that AHP allows decision makers to ensure the consistency of their judgments towards factors. Many recent studies successfully apply AHP in manufacturing sectors. According to Ho [20], one among the many successful applications of AHP is in the field of manufacturing, where a fair number of studies exist next to logistics. See the publications cited in [21-31] as examples in which AHP was successfully applied.

The step-by-step methodology of AHP application is detailed below (adapted from [32]).

Step 1: Select the list of attributes (drivers) related to an advanced sustainable manufacturing system combined from the assistance of existing literature review and from field experts' notions.

Step 2: From the assistance of the decision makers, create a pair-wise comparison on the given criteria. This comparison will be based on the Likert 5-point scale further modified to the Saaty scale for numerical ease. (See Table 1).

Step 3: Evalaute the global weights by formal arthimetic operations of AHP including normalization.

Step 4: Check the reliability of the results through the Consistency Index (C.I.) and the Consistency Ratio (C.R.)

Step 5: If the C.I. $<0.1$, then the verdict is satisfactory. Otherwise, pair-wise comparisons can be repeated to elucidate the error. The progression must be a cyclic process until the consistency condition is made satisfactory.

Step 6: Based on the final weights, the drivers of advanced sustaianble manufacturing are prioritized and further circulated to the case industry's decision makers in order to focus on the most highly-weighted driver.

The Saaty scale is the scale proposed in order to explain the relative importance of factors one over other. For instance, according to the Saaty scale, if criteria A and criteria B are measured to have a pair-wise comparison, and if $A$ is seven times more important than $B$, then we represent it as 8 ; if $B$ is seven times more important than $A$, then we represent it as $1 / 7$. As noted above, each and every criterion is analyzed by comparing one with another, and from this process, the weights of the criteria and sub-criteria are identified. 
Table 1. The Fundamental Scale absolute numbers.

\begin{tabular}{|c|c|c|}
\hline $\begin{array}{l}\text { Intensity of } \\
\text { Importance }\end{array}$ & Definition & Explanation \\
\hline 1 & Equal importance & Two activities contribute equally to the objective \\
\hline 2 & Weak or slight & \\
\hline 3 & Moderate importance & $\begin{array}{l}\text { Experience and judgment slightly favor one activity } \\
\text { over another }\end{array}$ \\
\hline 4 & Moderate plus & \\
\hline 5 & Strong importance & $\begin{array}{l}\text { Experience and judgment strongly favor one activity } \\
\text { over another }\end{array}$ \\
\hline 6 & Strong plus & \\
\hline 7 & $\begin{array}{l}\text { Very strong or } \\
\text { demonstrated importance }\end{array}$ & $\begin{array}{l}\text { An activity is favored very strongly over another; its } \\
\text { dominance demonstrated in practice }\end{array}$ \\
\hline 8 & Very, very strong & \\
\hline 9 & Extreme importance & $\begin{array}{l}\text { The evidence favoring one activity over another is of the } \\
\text { highest possible order of affirmation }\end{array}$ \\
\hline $\begin{array}{l}\text { Reciprocals } \\
\text { of above }\end{array}$ & $\begin{array}{l}\text { If activity } i \text { has one of the above } \\
\text { non-zero numbers assigned to it } \\
\text { when compared with activity } j \text {, } \\
\text { then } j \text { has the reciprocal value } \\
\text { when compared with } i\end{array}$ & A reasonable assumption \\
\hline $1.1-1.9$ & If the activities are very close & $\begin{array}{l}\text { May be difficult to assign the best value but when } \\
\text { compared with other contrasting activities, the size of } \\
\text { the small numbers would not be too noticeable, yet they } \\
\text { can still indicate the relative importance of the activities }\end{array}$ \\
\hline
\end{tabular}

\section{Application of the Proposed Model}

In order to validate the proposed model, it was applied in a case industry situated in southern India. This case company is one of the leading tire manufacturers in South India; they have been in the field since 1972, with six branches in and around South India, and their head office is located in Chennai. This case industry introduces many new innovative technical and technological strategies within their operations in order to sustain their business, and they have been successful for several years. However, due to the dynamic business world, this case industry began to lose their market share and to face peril due to the emergence of new competitors. Hence, they needed to improve their organizational culture in order to achieve more intangible benefits rather than focusing only on fiscal performance. By coincidence, our research team had just sent a proposal to this case industry explaining the new age of manufacturing and its benefits, so the company fortuitously accepted our research proposal. This case industry also supplies clients in some developed nations, so they were urged to improve their manufacturing strategy as a separate issue from their financial goals. Currently, this industry follows lean manufacturing standards with an emphasis on waste reduction; they had not yet considered automation technologies or sustainable strategies. Our study arrived at a point that might be highly useful for this firm to retain their position in a fluctuating business market. With the case industry's approval, our research team sought to validate the proposed model, which was categorized into three phases: (i) collection of drivers; (ii) application of AHP; and (iii) verification of results.

\subsection{Phase I: Collection of Common Drivers of Advanced Sustainable Manufacturing}

The first phase of the proposed model is to collect the common drivers of advanced sustainable manufacturing through the assistance of existing literatures and the opinions of field experts. A standard search procedure was followed using the key terms of the research, such as "advanced 
manufacturing", "sustainable manufacturing", "drivers", and so on. Reputable search databases, including Web of Science, Google Scholar, and Scopus were utilized. Twelve major drivers were originally selected. To complete a reliability check and to bridge the gap between researchers and practitioners, we gathered the field experts for a one-day workshop and circulated our list of drivers. After several rounds of discussions in which the experts offered insights into the processes that exist in virtual manufacturing, the original 12 drivers were expanded to 15 . Hence, this study utilizes 15 drivers recommended for analysis, as shown in Table 2.

Table 2. Common drivers of advanced sustainable manufacturing.

\begin{tabular}{cll}
\hline S. No. & \multicolumn{1}{c}{ Drivers } & \multicolumn{1}{c}{ References } \\
\hline $\mathbf{1}$ & Quality (D1) & {$[33-35]$} \\
$\mathbf{2}$ & Market capabilities (D2) & {$[11,35,36]$} \\
$\mathbf{3}$ & Financial benefit (D3) & {$[35,36]$} \\
$\mathbf{4}$ & Supply chain requirements (D4) & Experts' opinion \\
$\mathbf{5}$ & Delivery speed and performance flexibility (D5) & Experts' opinion \\
$\mathbf{6}$ & Compliance with regulations (D6) & {$[35,36]$} \\
$\mathbf{7}$ & Green purchasing (D7) & {$[11,35]$} \\
$\mathbf{8}$ & Optimized usage of resources (D8) & {$[11,35]$} \\
$\mathbf{9}$ & Green innovation (D9) & {$[11,35]$} \\
$\mathbf{1 0}$ & Environmental conservation (D10) & {$[11,35]$} \\
$\mathbf{1 1}$ & Education and training (D11) & {$[35]$} \\
$\mathbf{1 2}$ & Employee welfares (D12) & {$[35]$} \\
$\mathbf{1 3}$ & Stakeholders (D13) & {$[11,35,36]$} \\
$\mathbf{1 4}$ & Internal motivations (D14) & Experts' opinion \\
$\mathbf{1 5}$ & Customers' expectations (D15) & {$[11,35,36]$} \\
\hline
\end{tabular}

\subsection{Phase II: Application of AHP}

Once the common drivers were collected, the next step was the analysis through analytical hierarchy process (AHP). Because the conceptual and preliminary steps of AHP were explained in previous sections, we list here the four basic steps.

- Step 1: Based on the replies of case industry decision makers and the support of the Saaty scale, a pair-wise comparison among the collected common drivers of advanced sustainable manufacturing was made, which is shown in Table 3.

- Step 2: The pair-wise comparison matrix was normalized with standard arithmetic operations to form a normalized matrix, which has elements ranging from 0 to 1 . The normalized matrix is shown in Table 4.

- Step 3: From the normalized matrix, Eigenvalues were obtained and posed for a consistency check in order to ensure that the consistency ratio should be less than 0.1 .

- Step 4: Finally, the priority of the factors are ranked based on the Eigenvalues obtained by each driver. The rank, along with the priority of the drivers, is shown in Table 5. 
Table 3. Pair-wise comparison of drivers of advanced sustainable manufacturing.

\begin{tabular}{cccccccccccccccc}
\hline & D1 & D2 & D3 & D4 & D5 & D6 & D7 & D8 & D9 & D10 & D11 & D12 & D13 & D14 & D15 \\
\hline D1 & 1 & 9 & 2 & 9 & 6 & 7 & 9 & 9 & 9 & 8 & 9 & 9 & 4 & 9 & 5 \\
D2 & $1 / 9$ & 1 & $1 / 9$ & $1 / 6$ & $1 / 9$ & $1 / 9$ & $1 / 8$ & $1 / 7$ & $1 / 5$ & $1 / 9$ & $1 / 4$ & $1 / 3$ & $1 / 9$ & $1 / 2$ & $1 / 9$ \\
D3 & $1 / 2$ & 9 & 1 & 9 & 4 & 5 & 8 & 7 & 9 & 8 & 9 & 9 & 2 & 9 & 3 \\
D4 & $1 / 9$ & 6 & $1 / 9$ & 1 & $1 / 6$ & $1 / 5$ & $1 / 2$ & $1 / 3$ & 2 & $1 / 4$ & 3 & 4 & $1 / 9$ & 5 & $1 / 9$ \\
D5 & $1 / 6$ & 9 & $1 / 4$ & 6 & 1 & 2 & 5 & 4 & 7 & 3 & 8 & 9 & $1 / 3$ & 9 & $1 / 2$ \\
D6 & $1 / 7$ & 9 & $1 / 5$ & 5 & $1 / 2$ & 1 & 4 & 3 & 6 & 2 & 7 & 8 & $1 / 4$ & 9 & $1 / 3$ \\
D7 & $1 / 9$ & 8 & $1 / 8$ & 2 & $1 / 5$ & $1 / 4$ & 1 & $1 / 2$ & 3 & $1 / 3$ & 4 & 5 & $1 / 7$ & 6 & $1 / 6$ \\
D8 & $1 / 9$ & 7 & $1 / 7$ & 3 & $1 / 4$ & $1 / 3$ & 2 & 1 & 4 & $1 / 2$ & 5 & 6 & $1 / 6$ & 7 & $1 / 5$ \\
D9 & $1 / 9$ & 5 & $1 / 9$ & $1 / 2$ & $1 / 7$ & $1 / 6$ & $1 / 3$ & $1 / 4$ & 1 & $1 / 5$ & 2 & 3 & $1 / 9$ & 4 & $1 / 9$ \\
D10 & $1 / 8$ & 9 & $1 / 8$ & 4 & $1 / 3$ & $1 / 2$ & 3 & 2 & 5 & 1 & 6 & 7 & $1 / 5$ & 8 & $1 / 4$ \\
D11 & $1 / 9$ & 4 & $1 / 9$ & $1 / 3$ & $1 / 8$ & $1 / 7$ & $1 / 4$ & $1 / 5$ & $1 / 2$ & $1 / 6$ & 1 & 2 & $1 / 9$ & 3 & $1 / 9$ \\
D12 & $1 / 9$ & 3 & $1 / 9$ & $1 / 4$ & $1 / 9$ & $1 / 8$ & $1 / 5$ & $1 / 6$ & $1 / 3$ & $1 / 7$ & $1 / 2$ & 1 & $1 / 9$ & 2 & $1 / 9$ \\
D13 & $1 / 4$ & 9 & $1 / 2$ & 9 & 3 & 4 & 7 & 6 & 9 & 5 & 9 & 9 & 1 & 9 & 2 \\
D14 & $1 / 9$ & 2 & $1 / 9$ & $1 / 5$ & $1 / 9$ & 9 & $1 / 6$ & $1 / 7$ & $1 / 4$ & $1 / 8$ & $1 / 2$ & 2 & $1 / 9$ & 1 & $1 / 9$ \\
D15 & $1 / 5$ & 9 & $1 / 3$ & 9 & 2 & 3 & 6 & 5 & 9 & 4 & 9 & 9 & $1 / 2$ & 9 & 1 \\
\hline
\end{tabular}

Table 4. Normalized matrix.

\begin{tabular}{|c|c|c|c|c|c|c|c|c|c|c|c|c|c|c|c|}
\hline & D1 & D2 & D3 & D4 & D5 & D6 & D7 & D8 & D9 & D10 & D11 & D12 & D13 & D14 & D15 \\
\hline D1 & 5 & 1 & 4 & & 2 & 3 & 33 & 232 & 38 & 44 & 23 & 08 & 432 & 99 & 381 \\
\hline D2 & 34 & 010 & 1 & 3 & & & & 0.004 & & & & & 012 & 006 & .008 \\
\hline D3 & 0.153 & 0.091 & 0.187 & 0.154 & 0.222 & 0.152 & 0.172 & 0.181 & 0.138 & 0.244 & 0.123 & 0.108 & 0.216 & 0.099 & 0.229 \\
\hline D4 & 0.034 & 0.061 & 0.021 & 0.017 & 0.009 & 0.006 & 0.011 & 0.009 & 0.031 & 0.008 & 0.041 & 0.048 & 0.012 & 0.055 & .008 \\
\hline D5 & 0.051 & 0.091 & 047 & 3 & 5 & 0.061 & 0.107 & 0.103 & 0.107 & 0.091 & 99 & 88 & 0.036 & 0.099 & 0.038 \\
\hline D6 & 0.044 & 0.091 & 0.037 & 0.086 & 0.028 & 0.030 & 0.086 & 0.077 & 0.092 & 0.061 & 0.096 & 0.096 & 0.027 & 0.099 & 0.025 \\
\hline D7 & 0.034 & 0.081 & 0.023 & 0.034 & 0.011 & 0.008 & 0.021 & 0.013 & 0.046 & 0.010 & 0.055 & 0.060 & 0.015 & 0.066 & 0.013 \\
\hline D8 & 0.034 & 0.071 & 0.027 & 0.051 & 0.014 & 0.010 & 0.043 & 0.026 & 0.061 & 0.015 & & 0.072 & 0.018 & 0.077 & 0.015 \\
\hline D9 & 0.034 & 0.051 & & 0.009 & 0.000 & 0.005 & 0.007 & 0.006 & 0.015 & 0.006 & 27 & 0.036 & 0.012 & 0.044 & 0.008 \\
\hline D10 & 0.038 & 0.091 & 0.023 & 0.068 & 0.018 & 0.015 & 0.064 & 0.052 & 0.077 & 0.030 & 0.082 & 0.084 & 0.022 & 0.088 & 0.019 \\
\hline D11 & 0.034 & 0.040 & 0.021 & 0.006 & 0.007 & 0.004 & 0.005 & 0.005 & 0.008 & 0.005 & 0.014 & 0.024 & 0.012 & 0.033 & 0.008 \\
\hline D12 & 0.034 & 0.030 & 0.021 & 0.004 & 0.006 & 0.004 & 0.004 & 0.004 & 0.005 & 0.004 & 0.007 & 0.012 & 0.012 & 0.022 & 0.008 \\
\hline D13 & 0.076 & 0.091 & 0.094 & 0.154 & 0.100 & $0.1 \angle 2$ & 0.150 & 0.155 & 0.138 & 0.152 & 0.123 & 0.108 & 0.108 & 0.099 & 0.152 \\
\hline D14 & 0.034 & 0.020 & 0.021 & 0.003 & 0.006 & 0.274 & 0.004 & 0.004 & 0.004 & 0.004 & 0.007 & 0.024 & 0.012 & 0.011 & 0.008 \\
\hline D15 & 0.061 & 0.091 & 0.062 & 0.154 & 0.111 & 0.091 & 0.129 & 0.129 & 0.138 & 0.122 & 0.123 & 0.108 & 0.054 & 0.099 & 0.076 \\
\hline
\end{tabular}

Table 5. Ranks and priority among drivers.

\begin{tabular}{clcc}
\hline S. No. & \multicolumn{1}{c}{ Drivers } & Eigenvalue & Rank \\
\hline $\mathbf{1}$ & Quality (D1) & 0.2335 & $\mathbf{1}$ \\
$\mathbf{2}$ & Market capabilities (D2) & 0.00832 & $\mathbf{1 5}$ \\
$\mathbf{3}$ & Financial benefit (D3) & 0.1684 & $\mathbf{2}$ \\
$\mathbf{4}$ & Supply chain requirements (D4) & 0.02488 & $\mathbf{1 0}$ \\
$\mathbf{5}$ & Delivery speed and performance flexibility (D5) & 0.08216 & $\mathbf{5}$ \\
$\mathbf{6}$ & Compliance with regulations (D6) & 0.0659 & $\mathbf{6}$ \\
$\mathbf{7}$ & Green purchasing (D7) & 0.03298 & $\mathbf{9}$ \\
$\mathbf{8}$ & Optimized usage of resources (D8) & 0.04054 & $\mathbf{8}$ \\
$\mathbf{9}$ & Green innovation (D9) & 0.01949 & $\mathbf{1 1}$ \\
$\mathbf{1 0}$ & Environmental conservation (D10) & 0.05201 & $\mathbf{7}$ \\
$\mathbf{1 1}$ & Education and training (D11) & 0.01525 & $\mathbf{1 2}$ \\
$\mathbf{1 2}$ & Employee welfares (D12) & 0.01203 & $\mathbf{1 3}$ \\
$\mathbf{1 3}$ & Stakeholders (D13) & 0.1291 & $\mathbf{3}$ \\
$\mathbf{1 4}$ & Internal motivations (D14) & 0.00975 & $\mathbf{1 4}$ \\
$\mathbf{1 5}$ & Customers' expectations (D15) & 0.1057 & $\mathbf{4}$ \\
\hline
\end{tabular}




\subsection{Phase III: Result Validation}

Although the decision makers from the case industry provided the in-depth problem concepts, we wanted to check the reliability of the results. We compared the results obtained with the existing literature and with the case decision makers. A detailed description of this phase is documented in upcoming sections.

\section{Results and Discussions}

This section presented the results obtained from the study; this research aims to analyze the drivers of advanced sustainable manufacturing systems with the assistance of AHP. 15 drivers, collected from literature support and from field experts, are further analyzed with the help of the case industry's managers. The ranks and priority of the common drivers of advanced manufacturing technology are shown in Table 5.

Table 5 shows that Quality (D1) holds first position among the common drivers of advanced sustainable manufacturing with its Eigenvalue of 0.2335. Next, Financial benefit (D3) captures second place with the weights of 0.1684 , and the least driver of advanced sustainable manufacturing is reported as Market capabilities (D2). The other drivers, ranked by priority, are as follows: D1 $>$ D3 $>$ D13 $>\mathrm{D} 15>\mathrm{D} 5>\mathrm{D} 6>\mathrm{D} 10>\mathrm{D} 8>\mathrm{D} 7>\mathrm{D} 4>\mathrm{D} 9>\mathrm{D} 11>\mathrm{D} 13>\mathrm{D} 14>\mathrm{D} 2$. In order to validate the results, a two-way analysis was applied. Initially, the results are compared with the selections from existing literature and the acknowledgements of researchers. Secondly, we shared the results with the case industry decision makers. Joung's publication [34] offers an important observation. He points out that while many parameters and indicators exist in the current contemporary manufacturing environment, new strategies are mainly developed to maintain standards and to preserve resources without compromising quality. This statement reinforces a central result from our study, that quality is a primary factor that motivates firms to adopt new strategies.

When the results were shared with the case industry decision makers, they were surprised to learn that Quality (D1) was the priority driver. They expected some new factor to be revealed as central to the implementation of an advanced strategy. However, because the fundamental element of quality emerged as first priority, that ranking helped to establish that the decision makers needed to rethink their approach toward implementing sustainability into their manufacturing strategies. Our results reaffirmed the importance of quality and provided the decision makers with the motivation to become more self-aware.

This study provides countless managerial implications and serves both scientific and societal contributions. For managers, integrating automation technologies with sustainable practices can increase the company's financial benefits and may improve intangible factors on their organizational development. Furthermore, this integration has the potential to attract foreign clients, bringing globalization efforts to a developing nation like India. This study assists the shop floor managers to identify essential drivers for implementing advanced sustainable manufacturing in their firm. It also points out other influential drivers, so managers can consider a range of options. This study can be considered as a novel research effort, owing to the exploration of the advanced sustainable manufacturing context whereas previous studies examined only one of the themes. Apart from its scientific contributions, this study also considered social elements such as stakeholder satisfaction (including that of customers), resources conservation, green concerns, employee ergonomics, safety, and so on. An important element of this study is that it focuses on a developing nation; hence, this study might helpful in other Indian manufacturing sectors in order to eliminate cumbersome practices that restrict progress. This study also explains the importance of advanced sustainable manufacturing so it is likely to motivate shop floor and top-level managers to adopt relevant sustainable technology. This study bridges the literature gap by providing in-depth insights to assist practitioners in the successful implementation of advanced sustainable manufacturing. 


\section{Conclusions}

This study's objective was to explore the necessity of adding sustainable strategies into advanced manufacturing systems, and we determined that an effective first step was to identify strategy drivers and practices. We analyzed the drivers, collected both from literature resources and from experts' opinions, and created a model framework which we validated with an Indian case industry. We utilized the analytical hierarchy process (AHP) because it is a skilful tool to identify weights of factors under multi criteria. Our study revealed that "Quality" (D1) is the major driver of advanced sustainable manufacturing systems, as has been covered in the previous sections. Our study has provided both scientific and technical contributions, but includes some limitations. The Indian context is very multicultural with various political backgrounds, and this study considered a case industry situated in southern region of India. Studies done in other regions of India might reach different results. Future studies may wish to explore similar concepts with a statistical background. Our study may serve as a pioneer in the field, and it may be used as benchmark when employed in other political settings or in different developing countries.

Acknowledgments: The authors are very grateful for the kind comments raised by the Assistant Editor and the anonymous reviewers which led to important improvement of this paper. The authors wish to thank Kannan Govindan, Head of the Center for Engineering Operations Management, Department of Technology and Innovation, University of Southern Denmark for providing enough support to carry out this research.

Author Contributions: Madan Shankar and Devika Kannan contributed to the theoretical development, the writing, to refining and strengthening the paper's findings, expositions, and managerial implications. Udhaya Kumar contributed to refining and strengthening the paper's expositions and case study part of the paper.

Conflicts of Interest: The authors declare no conflict of interest.

\section{References}

1. Kastalli, I.V.; Van Looy, B. Servitization: Disentangling the impact of service business model innovation on manufacturing firm performance. J. Oper. Manag. 2013, 31, 169-180. [CrossRef]

2. Rusinko, C.A. Green manufacturing: An evaluation of environmentally sustainable manufacturing practices and their impact on competitive outcomes. IEEE Trans. Eng. Manag. 2007, 54, 445-454. [CrossRef]

3. Cousins, P.D.; Handfield, R.B.; Lawson, B.; Petersen, K.J. Creating supply chain relational capital: The impact of formal and informal socialization processes. J. Oper. Manag. 2006, 24, 851-863. [CrossRef]

4. Tao, F.; Cheng, Y.; Zhang, L.; Nee, A.Y.C. Advanced manufacturing systems: Socialization characteristics and trends. J. Intell. Manuf. 2014. [CrossRef]

5. Infosys. Global Manufacturing Study Shows Early Signs of Adoption of Groundbreaking Machine-to-Data Technologies with China Leading the Way. Available online: https://www.infosys.com/newsroom/pressreleases/Pages/strategies-industrial-manufacturing-worldwide.aspx (accessed on 13 May 2016).

6. Global Manufacturing Outlook. Available online: https://www.kpmg.com/CN/en/IssuesAndInsights / ArticlesPublications/Documents/Global-Manufacturing-Outlook-O-201506.pdf (accessed on 18 August 2015).

7. Zhu, Q.; Lujia, F.; Mayyas, A.; Omar, M.A.; Al-Hammadi, Y.; Al Saleh, S. Production energy optimization using low dynamic programming, a decision support tool for sustainable manufacturing. J. Clean. Prod. 2015, 105, 178-183. [CrossRef]

8. Lee, D.M.; Drake, P.R. A portfolio model for component purchasing strategy and the case study of two South Korean elevator manufacturers. Int. J. Prod. Res. 2010, 48, 6651-6682. [CrossRef]

9. Ishizaka, A.; Pearman, C.; Nemery, P. AHPSort: An AHP-based method for sorting problems. Int. J. Prod. Res. 2012, 50, 4767-4784. [CrossRef]

10. Malik, M.M.; Abdallah, S.; Hussain, M. Assessing supplier environmental performance: Applying Analytical Hierarchical Process in the United Arab Emirates healthcare chain. Renew. Sustain. Energy Rev. 2016, 55, 1313-1321. [CrossRef]

11. Govindan, K.; Diabat, A.; Shankar, K.M. Analyzing the drivers of green manufacturing with fuzzy approach. J. Clean. Prod. 2015, 96, 182-193. [CrossRef]

12. Dyer, J.S. Remarks on the analytic hierarchy process. Manag. Sci. 1990, 36, 249-258. [CrossRef]

13. Harker, P.T.; Vargas, L.G. Reply to 'Remarks on the analytic hierarchy process' by J.S. Dyer. Manag. Sci. 1990, 36, 269-273. [CrossRef] 
14. Saaty, T.L. An exposition of the AHP in reply to the paper 'Remarks on the analytic hierarchy process'. Manag. Sci. 1990, 36, 259-268. [CrossRef]

15. Kannan, G.; Haq, A.N.; Sasikumar, P.; Arunachalam, S. Analysis and selection of green suppliers using interpretative structural modelling and analytic hierarchy process. Int. J. Manag. Decis. Mak. 2008, 9, 163-182. [CrossRef]

16. Govindan, K.; Kaliyan, M.; Kannan, D.; Haq, A.N. Barriers analysis for green supply chain management implementation in Indian industries using analytic hierarchy process. Int. J. Prod. Econ. 2014, 147, 555-568. [CrossRef]

17. Mathiyazhagan, K.; Govindan, K.; Noorul Haq, A. Pressure analysis for green supply chain management implementation in Indian industries using analytic hierarchy process. Int. J. Prod. Res. 2014, 52, 188-202. [CrossRef]

18. Kannan, G.; Murugesan, P.; Haq, A.N. 3PRLP's selection using an integrated analytic hierarchy process and linear programming. Int. J. Serv. Technol. Manag. 2009, 12, 61-80. [CrossRef]

19. Liberatore, M.J.; Nydick, R.L. The analytic hierarchy process in medical and health care decision making: A literature review. Eur. J. Oper. Res. 2008, 189, 194-207. [CrossRef]

20. Ho, W. Integrated analytic hierarchy process and its applications-A literature review. Eur. J. Oper. Res. 2008, 186, 211-228. [CrossRef]

21. Akgunduz, A.; Zetu, D.; Banerjee, P.; Liang, D. Evaluation of sub-component alternatives in product design processes. Robot. Comput. Integr. Manuf. 2002, 18, 69-81. [CrossRef]

22. Braglia, M.; Gabbrielli, R.; Miconi, D. Material handling device selection in cellular manufacturing. J. Multi-Criteria Decis. Anal. 2001, 10, 303-315. [CrossRef]

23. Hsiao, S.W. Concurrent design method for developing a new product. Int. J. Ind. Ergon. 2002, 29 , 41-55. [CrossRef]

24. Chang, P.T.; Lo, Y.T. Modelling of job-shop scheduling with multiple quantitative and qualitative objectives and a GA/TS mixture approach. Int. J. Comput. Integr. Manuf. 2001, 14, 367-384. [CrossRef]

25. Kwong, C.K.; Bai, H. A fuzzy AHP approach to the determination of importance weights of customer requirements in quality function deployment. J. Intell. Manuf. 2002, 13, 367-377. [CrossRef]

26. Madu, C.N.; Kuei, C.; Madu, I.E. A hierarchic metric approach for integration of green issues in manufacturing: A paper recycling application. J. Environ. Manag. 2002, 64, 261-272. [CrossRef]

27. Shinno, H.; Yoshioka, H.; Marpaung, S.; Hachiga, S. Quantitative SWOT analysis on global competitiveness of machine tool industry. J. Eng. Des. 2006, 17, 251-258. [CrossRef]

28. Partovi, F.Y. A quality function deployment approach to strategic capital budgeting. Eng. Econ. 1999, 44, 239-260. [CrossRef]

29. Wang, H.; Xie, M.; Goh, T.N. A comparative study of the prioritization matrix method and the analytic hierarchy process technique in quality function deployment. Total Qual. Manag. 1998, 9, 421-430. [CrossRef]

30. Yang, T.; Kuo, C. A hierarchical AHP/DEA methodology for the facilities layout design problem. Eur. J. Oper. Res. 2003, 147, 128-136. [CrossRef]

31. Zakarian, A.; Kusiak, A. Forming teams: An analytic approach. IIE Trans. 1999, 31, 85-97. [CrossRef]

32. Xu, L.; Kumar, D.T.; Shankar, K.M.; Kannan, D.; Chen, G. Analyzing criteria and sub-criteria for the corporate social responsibility-based supplier selection process using AHP. Int. J. Adv. Manuf. Technol. 2013, 68, 907-916. [CrossRef]

33. Son, Y.K.; Park, C.S. Economic measure of productivity, quality and flexibility in advanced manufacturing systems. J. Manuf. Syst. 1987, 6, 193-207. [CrossRef]

34. Joung, C.B.; Carrell, J.; Sarkar, P.; Feng, S.C. Categorization of indicators for sustainable manufacturing. Ecol. Indic. 2013, 24, 148-157. [CrossRef]

35. Bey, N.; Hauschild, M.Z.; McAloone, T.C. Drivers and barriers for implementation of environmental strategies in manufacturing companies. CIRP Ann. Manuf. Technol. 2013, 62, 43-46. [CrossRef]

36. Singh Sangwan, K.; Bhamu, J.; Mehta, D. Development of lean manufacturing implementation drivers for Indian ceramic industry. Int. J. Product. Perform. Manag. 2014, 63, 569-587. [CrossRef]

(C) 2016 by the authors; licensee MDPI, Basel, Switzerland. This article is an open access article distributed under the terms and conditions of the Creative Commons Attribution (CC-BY) license (http:/ / creativecommons.org/licenses/by/4.0/). 